\title{
Can inflammatory biomarkers play a role in the inclusion of patients with acute myocardial infarction in cardiac rehabilitation programs?
}

\author{
DĂDÂRLAT-POP Alexandra ${ }^{1,2}$, ROȘIANU Horea ${ }^{1,2 \dagger}$, POPTILE Renaldo ${ }^{1}$, TOMOAIA Raluca ${ }^{1,2 *}$, \\ BEYER Ruxandra ${ }^{2}$, ȘERBAN Adela ${ }^{1,2}$
}

Editor: Mihail HOTETEU, Romanian Association of Balneology, hoteteu@yahoo.com

Reviewers: Constantin Munteanu and Gabriela Dogaru

*Corresponding author: Tomoaia Raluca, MD, e-mail: raluca.tomoaia@gmail.com;

$\dagger$ These authors contributed equally to this study

${ }^{1}$ Department of Cardiology, "Iuliu Haţieganu" University of Medicine and Pharmacy, Cluj-Napoca, Romania

${ }^{2}$ Cardiology Department, Heart Institute Niculae Stăncioiu, Cluj-Napoca, Romania

\begin{abstract}
Introduction: In spite of the enormous progress made over the last decades, acute coronary syndromes remain the leading cause of death globally. Inflammation plays an important role in coronary artery disease development. Although the role of inflammatory biomarkers in acute obstructive myocardial infarction is well established, there is no data regarding the potential differences between acute myocardial infarction (AMI) with ST segment elevation, AMI without ST segment elevation (NONSTEMI) and non-obstructive acute myocardial infarction (MINOCA), respectively. Also, it is well known that cardiac rehabilitation of acute myocardial infarction survivors significantly improves their long-term prognosis.

Aim of the study: To asses the possible existing differences between patients with STEMI, NON-STEMI and MINOCA in terms of clinical and paraclinical parameters, especially inflammatory biomarkers. A second objective of our study was to describe the relationship between inflammatory, cardiac necrosis enzymes and left ventricle systolic function.

Material and methods: The study included 35 adult patients admitted in the Cardiology service of the Niculae Stăncioiu Heart Institute, Cluj-Napoca with acute myocardial infarction. Demographic, clinical, echocardiographic and laboratory data were analyzed. Patients were divided into 3 groups, 19 patients $(54.2 \%)$ were diagnosed with STEMI- group 1, 9 patients $(25.7 \%)$ with NON-STEMI- group 2 and 7 patients (20\%) with MINOCA- group 3, respectively. Dosage of serum inflammatory markers was performed on the day of admission.

Results and conclusion: The most common associated cardiovascular risk factor was arterial hypertension (65.7\% of patients). Markers of myocardial necrosis (CK, CK-MB, hs Troponin) were significantly higher in patients with STEMI (p <0.05) in comparison with NON-STEMI and MINOCA patients. Congestive heart failure was most frequently encountered in STEMI patients. hsCRP value was higher among patients with STEMI. The value of ESR was significantly higher among patients with NON-STEMI. Serial dosage of inflammation biomarkers in patients with recent acute myocardial infarction may serve as valuable risk stratification instruments and also for functional capacity and recovery status assessment in patients included in cardiac rehabilitation programs.
\end{abstract}

Keywords: acute coronary syndrome; inflammatory biomarkers; non-obstructive acute myocardial infarction,

\section{INTRODUCTION}

Inflammation plays a major role in atherosclerotic pathogenesis and coronary artery disease development (1). Moreover, in acute coronary syndromes an intense inflammatory response occurs. Therefore, the role of inflammatory cells is not limited to the acute event but drives the chronic atherosclerotic process as well (2). Moreover, inflammatory biomarkers provide accurate information regarding pathophysiology, prognosis, risk stratification and optimal management in ischemic cardiopathy (3).

The role of traditional inflammatory biomarkers in acute coronary syndromes has been already studied in large clinical trials and they have been validated as valuable predictors of short and also long-term prognosis (4). It is also important to point out that the medication used in the treatment of acute myocardial infarction has a proven anti-inflammatory role (1). Studies have shown that marked leukocytosis during myocardial infarction is associated with a high rate of mortality, indeed an independent prognostic marker for the development of heart failure and cardiogenic shock (2).

Also, in recent literature, there has been increasing interest in neutrophil-to-lymphocyte ratio (NLR) as an independent marker of mortality and morbidity in cardiovascular diseases: the negative prognosis was associated with high NLR values (4).

Although the role of inflammatory biomarkers in acute obstructive myocardial infarction is well established, there is no data regarding the potential differences between acute myocardial infarction (AMI) with ST 
segment elevation (STEMI), AMI without ST segment elevation (NON-STEMI) and non-obstructive acute myocardial infarction (MINOCA), respectively. MINOCA is a condition that has been shown to have comparable morbi-mortality to that of acute coronary syndrome with obstructive coronary disease. But the underlying etiology is extremely heterogenic making the assessment and management challenging (5). By describing the potential differences in terms of demographic, clinical and paraclinical variables we can aid some valuable information for an appropriate workout and treatment of MINOCA patients. Despite the existence of numerous clinical studies, no specific inflammatory biomarkers are recommended by the current guidelines in the standard work-out of patients with acute coronary syndromes. At present there is scattered data regarding the

Therefore, this study aimed to asses the possible existing differences between patients with STEMI, NON-STEMI and MINOCA in terms of clinical and paraclinical parameters, especially inflammatory markers: serum leukocytes values, NRL, high-sensitivity C-reactive Protein (hs-CRP), ferritin, fibrinogen and erythrocyte sedimentation rate (ESR) values. A second objective of our study was to describe the relationship between inflammatory, cardiac necrosis enzymes and left ventricle systolic function.

\section{Material and methods}

The study included 35 adult patients admitted in the Cardiology service of the Niculae Stăncioiu Heart Institute, Cluj-Napoca with acute myocardial infarction. Acute myocardial infarction was diagnosed according to the current ESC guidelines (2,5-7). The exclusion criteria were represented by concomitant acute infections or active inflammatory diseases, conditions that could interfere with the prognostic accuracy of the studied markers.

Demographic, clinical, echocardiographic and laboratory data were analyzed. Patients were divided into 3 groups according to the presentation of the acute coronary event and coronary angiography findings - STEMI, NONSTEMI and MINOCA patients.

Dosage of serum inflammatory markers was performed on the day of admission and their measurement was carried out by qualified personnel in the laboratory of the Heart Institute Niculae Stăncioiu. The following inflammatory biomarkers were analyzed: hs C-reactive protein, hs troponin I, leukocytes, NLR, ferritin.

\section{Statistical analysis}

Statistical analysis was performed using MedCalc software (v 10.3.0.0, MedCalc Software, Ostend, Belgium). The normal distribution of the variables was assessed using the Kolmogorov-Smirnov test. Categorical variables are summarized using frequencies and percentages, whereas numerical variables are summarized using mean, $\mathrm{SD}$, median, and quartiles. To perform comparisons between groups, we used ANOVA, respectively Kruskal-Wallis (for numerical data) or Chi square test (for non-numerical data). The Pearson and Spearman coefficients were used to describe the correlations between the data. A p value $<0.05$ was defined as statistically significant.

\section{Results}

\section{Baseline characteristic}

The baseline characteristics of the patients are summarized in Table I.

Table I. The characteristics of the patients included in the study regarding clinical, demographic and paraclinical data.

\begin{tabular}{|c|c|}
\hline Variables & Values \\
\hline Mean age $\pm \mathrm{SD}$ & $59,778 \pm 13,27$ \\
\hline Women - no (\%) & $27,77 \%$ \\
\hline hs Troponin I -ng/ml (mean \pm SD) & $108,828 \pm 3,93$ \\
\hline hsCRP- mg/L (mean \pm SD) & $38,67 \pm 47,97$ \\
\hline Leucocytes value- $* 10^{2} /$ microl $($ mean $\pm \mathrm{SD})$ & $10,45 \pm 3,54$ \\
\hline $\mathrm{ESR}-\mathrm{mm}($ mean $\pm \mathrm{SD})$ & $22,18 \pm 13,36$ \\
\hline Fibrinogen levels - mg/dl (mean \pm SD) & $497,43 \pm 133,89$ \\
\hline Ferritin levels- microg/L (mean \pm SD) & $283,81 \pm 255,25$ \\
\hline NLR values (mean $\pm \mathrm{SD})$ & $0,704 \pm 0,11$ \\
\hline HDL-cholesterol-mg/dl (mean \pm SD) & $43,95 \pm 13,08$ \\
\hline LDL-cholesterol - mg/dl (mean $\pm \mathrm{SD})$ & $104,39 \pm 42,97$ \\
\hline Triglycerides - mg/dl (mean \pm SD) & $142,15 \pm 76,03$ \\
\hline Total Cholesterol - mg/dl (mean \pm SD) & $178,84 \pm 58,95$ \\
\hline Uric acid $-\mathrm{mg} / \mathrm{dl}($ mean $\pm \mathrm{SD})$ & $49,97 \pm 50,28$ \\
\hline Diabetes mellitus- no (\%) & $31,42 \%$ \\
\hline Arterial hypertension - no (\%) & $65,71 \%$ \\
\hline Glycemia - mg/dl $($ mean \pm SD) & $156,98 \pm 76,74$ \\
\hline Left ventricle ejection fraction- $\%($ mean \pm SD $)$ & $43 \pm 11,32$ \\
\hline
\end{tabular}

SD- standard deviation

Of the total (35) patients included in the study, only $27 \%$ were women. The most common associated cardiovascular risk factor was arterial hypertension (65.7\% of patients). Grade I hypertension was recorded in $11.4 \%$ of patients, grade II hypertension in $37.1 \%$, and grade III hypertension in $17.1 \% .40 \%$ of patients enrolled in the study were smokers.

Type 2 diabetes was seen in $31.4 \%$ of patients.

Patients were divided into 3 groups, 19 patients $(54.2 \%)$ were diagnosed with STEMI- group 1, 9 patients $(25.7 \%)$ with NON-STEMI- group 2 and 7 patients $(20 \%)$ with MINOCA- group 3, respectively - as you can see in Figure 1.

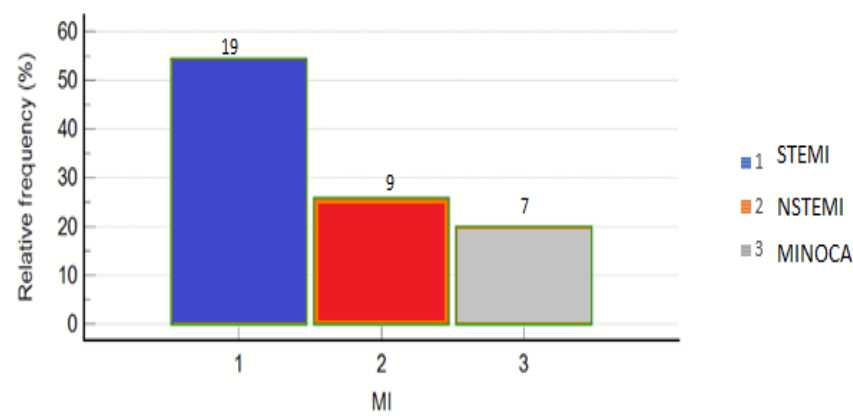

Figure 1. Patients divided into the 3 groups according to the acute coronary event. 
The proportion of type 2 diabetes mellitus was similar between the 3 groups of patients ( $p=0.13)$.

Table II presents the demographic, clinical and paraclinical characteristics of the 3 groups of patients.

Table II. Differences in demographic, clinical and paraclinical variables between the 3 groups.

\begin{tabular}{|c|c|c|c|}
\hline Variables & Group 1 & Group 2 & Group 3 \\
\hline Mean age \pm SD & $59,57 \pm 12,68$ & $63 \pm 9,69$ & $53,85 \pm 19,03$ \\
\hline Females - no (\%) & $31,58 \%$ & $11,11 \%$ & $42,86 \%$ \\
\hline $\begin{array}{l}\text { hs Troponin I - } \\
\mathrm{ng} / \mathrm{ml} \text { (mean } \pm \\
\mathrm{SD})\end{array}$ & $2,74 \pm 5,03$ & $0,89 \pm 0,95$ & $0,90 \pm 1,63$ \\
\hline $\begin{array}{l}\text { hsCRP- } \mathrm{mg} / \mathrm{L} \\
(\mathrm{mean} \pm \mathrm{SD})\end{array}$ & $51,50 \pm 55,86$ & $17,92 \pm 20,12$ & $15,21 \pm 12,11$ \\
\hline $\begin{array}{l}\text { Leucocytes } \\
\text { value- } \\
* 10^{2} / \text { microl } \\
(\text { mean } \pm \mathrm{SD})\end{array}$ & $11,24 \pm 3,37$ & $9,48 \pm 2.66$ & $9,55 \pm 4,81$ \\
\hline $\begin{array}{l}\text { ESR - mm (mean } \\
\pm \mathrm{SD})\end{array}$ & $22,83 \pm 11,05$ & $38,5 \pm 12,02$ & $10 \pm 5$ \\
\hline $\begin{array}{l}\text { Fibrinogen levels } \\
-\mathrm{mg} / \mathrm{dl} \text { (mean } \pm \\
\mathrm{SD} \text { ) }\end{array}$ & $\begin{array}{l}544,24 \pm 122,7 \\
5\end{array}$ & $\begin{array}{l}525,88 \pm 91,5 \\
3\end{array}$ & $347,06 \pm 82,15$ \\
\hline $\begin{array}{l}\text { NLR (mean } \pm \\
\text { SD) }\end{array}$ & $0,721 \pm 0,13$ & $0,695 \pm 0,04$ & $0,667 \pm 0,12$ \\
\hline $\begin{array}{l}\text { Creatin } \quad \text { Kinase } \\
(\mathrm{CK})-\mathrm{UI} / \mathrm{L} \\
(\mathrm{mean} \pm \mathrm{SD})\end{array}$ & $830 \pm 1095,67$ & $389 \pm 435,81$ & $\begin{array}{l}398,42 \pm 412,1 \\
4\end{array}$ \\
\hline $\begin{array}{l}\text { CK-MB- UI/L } \\
(m e a n \pm S D)\end{array}$ & $73,47 \pm 90,67$ & $36,21 \pm 19,20$ & $38,58 \pm 23,79$ \\
\hline $\begin{array}{l}\text { HDL-cholesterol } \\
-\mathrm{mg} / \mathrm{dl} \text { (mean } \pm \\
\mathrm{SD})\end{array}$ & $44,25 \pm 14,53$ & $41,46 \pm 12,69$ & $45,81 \pm 11,55$ \\
\hline $\begin{array}{l}\text { LDL-cholesterol } \\
-\mathrm{mg} / \mathrm{dl}(\text { mean } \pm \\
\text { SD) }\end{array}$ & $109,4 \pm 40,44$ & $\begin{array}{l}103,16 \pm 49,2 \\
0\end{array}$ & $94,71 \pm 47,97$ \\
\hline $\begin{array}{l}\text { Triglycerides }- \\
\mathrm{mg} / \mathrm{dl} \text { (mean } \pm \\
\mathrm{SD})\end{array}$ & $139,41 \pm 82,72$ & $\begin{array}{l}181,17 \pm 79,9 \\
1\end{array}$ & $109,8 \pm 35,38$ \\
\hline $\begin{array}{l}\text { Total Cholesterol } \\
-\mathrm{mg} / \mathrm{dl} \text { (media } \pm \\
\text { DS) }\end{array}$ & $183,92 \pm 45,81$ & $\begin{array}{l}184,52 \pm 85,1 \\
7\end{array}$ & $162,27 \pm 60,38$ \\
\hline $\begin{array}{l}\text { Uric acid }-\mathrm{mg} / \mathrm{dl} \\
(\text { media } \pm \text { DS })\end{array}$ & $60,41 \pm 65,03$ & $43,5 \pm 22,39$ & $29,95 \pm 9,75$ \\
\hline $\begin{array}{l}\text { Type } 2 \text { diabetes } \\
\text { mellitus- no }(\%)\end{array}$ & $36,84 \%$ & $33,33 \%$ & $14,29 \%$ \\
\hline $\begin{array}{l}\text { Arterial } \\
\text { hypertension - no } \\
(\%)\end{array}$ & $52,63 \%$ & $88,89 \%$ & $71,43 \%$ \\
\hline $\begin{array}{l}\text { Glycemia- mg/dl } \\
(\text { mean } \pm \mathrm{SD})\end{array}$ & $173,36 \pm 92.85$ & $\begin{array}{l}151,93 \pm 59,4 \\
8\end{array}$ & $119 \pm 14,67$ \\
\hline $\begin{array}{l}\text { Left ventricle } \\
\text { ejection fraction- } \\
\%(\text { mean } \pm \text { SD })\end{array}$ & $40,11 \pm 7,28$ & $42,66 \pm 13,53$ & $48,57 \pm 15,44$ \\
\hline $\begin{array}{l}\text { Sars-Cov2 } \\
\text { positive PCR - no } \\
(\%)\end{array}$ & $21,05 \%$ & $11,11 \%$ & $28,57 \%$ \\
\hline
\end{tabular}

Among the MINOCA patients, women represented the majority (55\%).
Markers of myocardial necrosis (CK, CK-MB, hs Troponin) were significantly higher in patients with STEMI $(\mathrm{p}<0.05)$ in comparison with NON-STEMI and MINOCA patients.

In terms of lipid fractions, there were no statistically significant differences between the 3 groups. In all groups, the average LDL cholesterol value exceeded 70 $\mathrm{mg} / \mathrm{dl}$.

Blood glucose levels were highest in the group of patients with STEMI.

Congestive heart failure was most frequently encountered in STEMI patients, as you can see in Table III.

Table III. NYHA functional class of heart failure in the 3 groups.

\begin{tabular}{|c|c|c|c|c|}
\hline $\begin{array}{l}\text { Heart Failure } \\
\text { NYHA } \\
\text { Functional } \\
\text { Class }\end{array}$ & Group 1 & Group 2 & Group 3 & P value \\
\hline Class I & 1 & 1 & 0 & \multirow[t]{5}{*}{0.08} \\
\hline Class II & 8 & 5 & 4 & \\
\hline Class III & 2 & 0 & 0 & \\
\hline Class IV & 0 & 1 & 0 & \\
\hline Total & $52.8 \%$ & $25 \%$ & $19.4 \%$ & \\
\hline
\end{tabular}

Patients with STEMI had a lower left ventricular ejection fraction (median value of $40 \%$ ) compared to other patients $-47.5 \%$ median value in patients with NONSTEMI and $45 \%$ in those with MINOCA, respectively. But no statistically significant difference was noticed $(\mathrm{p}=$ 0.1 ) - figure 2.

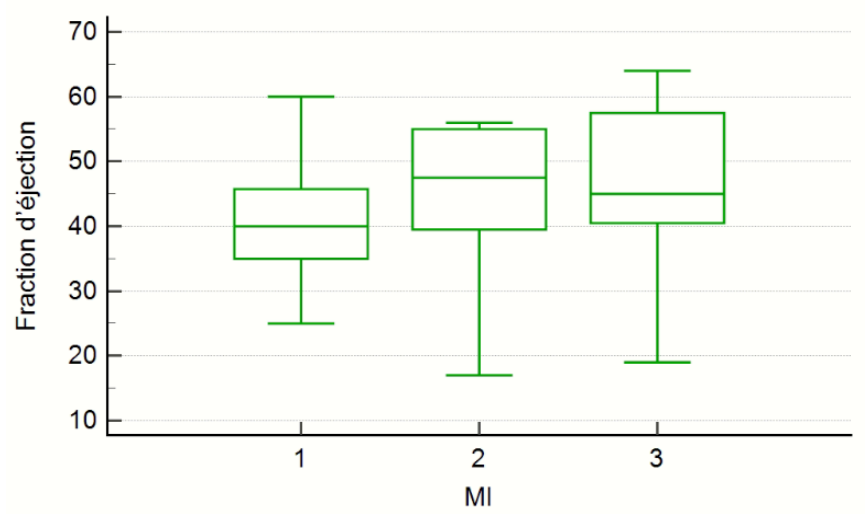

Figure 2. The value of the left ventricular ejection fraction in the 3 groups of patients.

hsCRP value was higher among patients in Group 1 (51.5 $\pm 55.86 \mathrm{mg} / \mathrm{L}$ ), compared to the other 2 groups- Figure 3 .

Figure 3. hsCRP values in the three groups.

The value of ESR was significantly higher among patients with NON-STEMI $(38.5 \pm 12.02 \mathrm{~mm}, \mathrm{p}=0.006)$ compared to patients with STEMI or MINOCA. The 


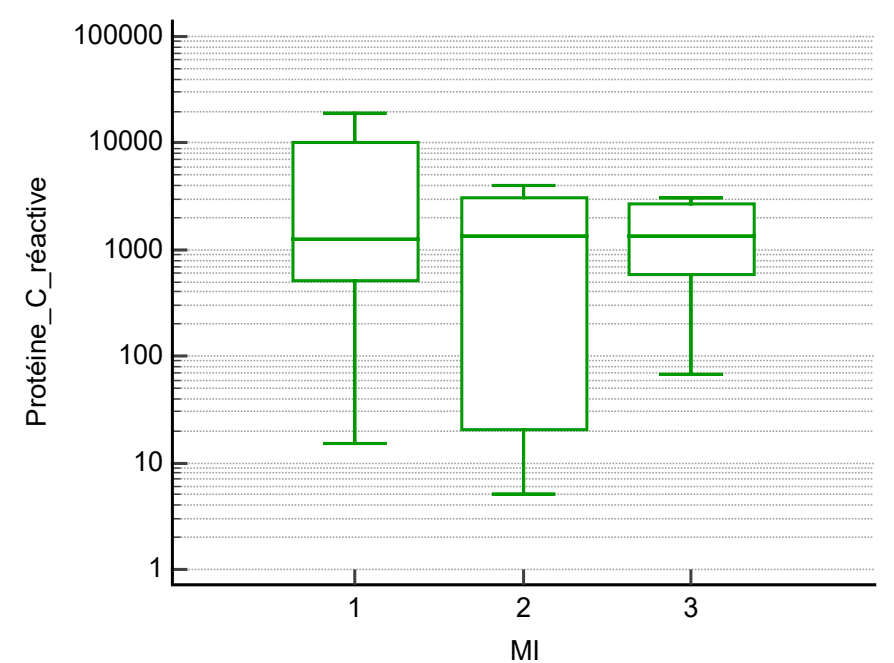

lowest values were recorded in patients with MINOCA Figure 4.

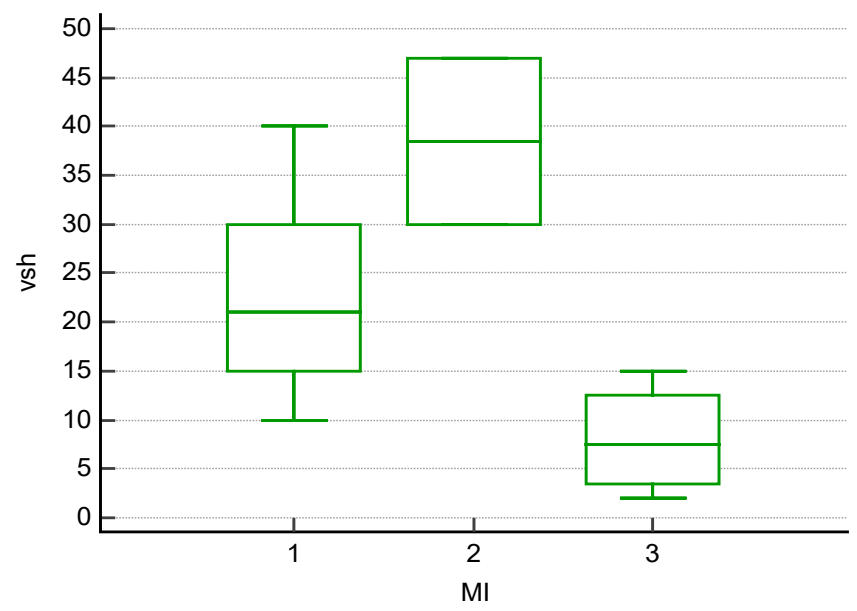

Figure 4. The value of ESR between the 3 groups of patients.

The value of serum fibrinogen was similar in the 3 groups $(\mathrm{p}=0.6)$.

Patients with STEMI showed slightly higher values of serum leukocytes compared to patients with NONSTTEMI and MINOCA, but this difference was not statistically significant $(\mathrm{p}=0.14)$ - figure 5 .

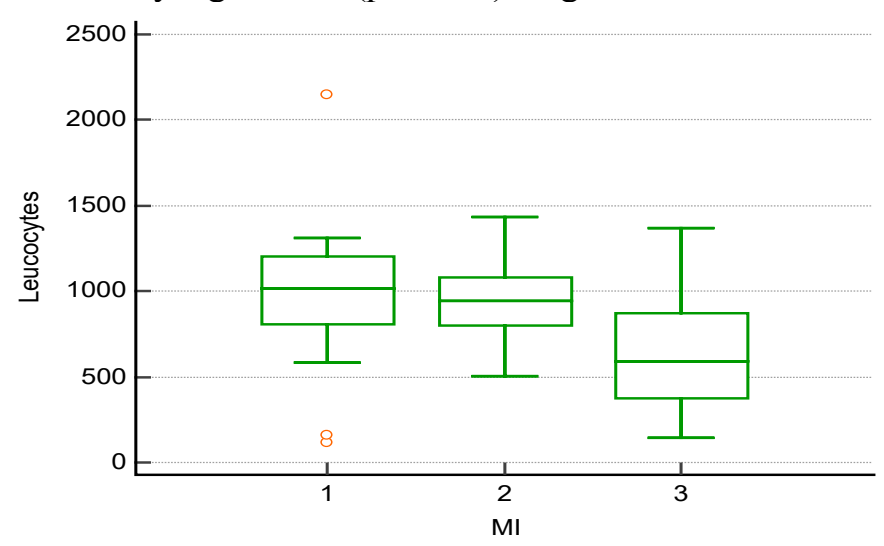

Figure 5. The value of blood leukocytes in the 3 groups of patients.
The ferritin value was not significantly different between groups $(\mathrm{p}=0.19)$.

\section{Discussion}

Cardiovascular disease is the leading cause of death globally, acute coronary syndromes (ACS) being responsible for $85 \%$ of the cardiovascular deaths (5). In Europe, cardiovascular diseases represent the main causes of death: $40 \%$ in men $(19 \%$ - ischemic heart disease) and $49 \%$ in women $(19 \%$ ischemic heart disease). In our country, cardiovascular diseases are the main cause of mortality: of these, acute coronary syndromes (ACS) are responsible for more than half of the deaths (8).

In STEMI patients transmural ischemia due to transient or persistent complete occlusion of the infarct-related coronary artery is present (5). In NON-STEMI patients, the infarct is subendocardial. MINOCA represents a heterogenous entity, being characterized by nonobstructive coronary artery on angiography (defined as no coronary artery stenosis $\geq 50 \%$ ). More commonly, MINOCA patients present as NSTEMI than STEMI (9). The existing studies present most frequently undifferentiated ACS cohorts, therefore this study aimed to provide separate demographic, clinical and paraclinical data between the 3 entities. In the current study we found distinct clinical data in MINOCA patients in comparison with those with conventional ACS. Patients with MINOCA were younger (median age was 54 years), predominantly affected women (55\%). A lower prevalence of diabetes was registered in MINOCA patients. Left ventricular ejection fraction was higher in MINOCA patients compared with STEMI and NONSTEMI patients.

Inflammation plays an important role in both the pathogenesis of ACS and also in post-myocardial infarction recovery. Moreover, the commonly used drugs in the treatment of ACS reduce the inflammatory process (10). There are studies demonstrating different inflammation kinetics between the entities of ACS (10). In our study, at the admission STEMI patients had a higher inflammatory state than NON-STEMI patients. Also, MINOCA patients presented a differential inflammatory pattern compared to STEMI and NONSTEMI patients. They presented lower levels of serum hsCRP, leucocytes, ESR and fibrinogen compared with the other 2 groups. It is demonstrated that the risk related to inflammation activation is not abolished by an invasive early approach (10-11).

One of the most studied markers of inflammation in acute myocardial infarction is hsCRP and studies have shown that it represents a strong predictor of cardiac adverse events $(2,12,13)$. At the same time, both leukocytosis and elevated serum fibrinogen are associated with a poor 
prognosis in patients with acute coronary events (2). However, the association between inflammatory markers and acute coronary events remains incompletely known today. Therefore, the present study aimed to asses the relationship between the usual inflammatory biomarkers hsCRP, leukocytes, fibrinogen, ESR, NLR and ferritin in patients with acute coronary events, depending on the etiology: STEMI, NON-STEMI and MINOCA.

Our study showed that the values of inflammatory markers were increased at hospitalization of patients with acute coronary events, regardless of etiology - STEMI, NON-STEMI, MINOCA, respectively. These results are in line with those of other recent studies (2). The current study showed that there are differences in the levels of inflammatory markers between patients with STEMI, NON-STEMI and MINOCA, respectively. Patients with STEMI had higher values of hsCRP and serum leukocytes than the rest of the patients. The value of all myocardial necrosis enzymes- hs Troponin, CK, CK-MB was higher in patients with STEMI, compared to the rest of the patients. The rest of the inflammatory markers fibrinogen, ferritin and NLR did not vary significantly between the 3 groups. We mention that the ESR value was higher in patients with NON-STEMI.

The left ventricular ejection fraction is an important predictive marker of poor long-term prognosis in patients with acute myocardial infarction $(1,3)$. At the same time, studies have shown that an ejection fraction $<40 \%$ in patients with acute myocardial infarction is associated with an increase in mortality at 1 year and an increase in the number of hospitalizations for heart failure (3). In the present study, the left ventricle ejection fraction values were significantly lower in patients with STEMI compared to NON-STEMI and MINOCA.

In line with the above mentioned data, patients with STEMI had higher inflammation biomarkers levels and a lower systolic function compared with NON-STEMI and MINOCA patients. Therefore, their long-term prognosis may be poorer than that of patients with NSTEMI and MINOCA. Therefore, one of the frequently asked questions is what else can be done for this category of patients. One of the answers is the long-term administration of cardioprotective medicine, which also relieves inflammation because the inflammatory process continues in the recovery phase of an AMI, also (5). On the other side, it is well documented that the inclusion of those patients without important AMI complications in cardiac rehabilitation programs reduces inflammation. AMI patients are enrolled in cardiac rehabilitation programs after an exercise stress testing (14). Cardiac rehabilitation programs have favorable effects in all patients with myocardial infarction, regardless of their etiology. These patient-oriented programs cab be performed in hospital or in the ambulatory cardiology unit. There is ample evidence that cardiac rehabilitation decreases inflammation and increases nitric oxide production (14-15). Regular training for 6 months in patients after AMI significantly reduces the local expression of TNF-alpha, IL-1 beta, IL-6 in skeletal muscles (14). Moreover, cardiac rehabilitation improves oxygen consumption, physical capacity, cardiac function (16). Studies show that the level of pro-inflammatory markers significantly decreases after the rehabilitation treatment in patients with AMI (16). In the future, we aim to enroll as many patients with recent AMI as possible in supervised physical training programs in specialized outpatient clinics. We will evaluate the link between inflammatory biomarkers levels and regular physical activity and capacity after 6 months of patientoriented rehabilitation care.

\section{Conclusion}

MINOCA patients presented a differential inflammatory pattern compared to STEMI and NON-STEMI patients. Patients with MINOCA were younger, had a lower prevalence of diabetes and a highr left ventricle ejection fraction. Also, inflammation kinetics were different between the entities of ACS. Patients with STEMI had higher values of hsCRP and serum leukocytes than the rest of the patients. The value of all myocardial necrosis enzymes- hs Troponin, CK, CK-MB was higher in patients with STEMI, compared to the rest of the patients. In the present study, the left ventricle ejection fraction values were significantly lower in patients with STEMI compared to NON-STEMI and MINOCA.

\section{References:}

1. Lüscher TF. Myocardial infarction: Mechanisms, diagnosis, and complications. Eur Heart J. 2015;36(16):947-9.

2. Ibanez B, James S, Agewall S, Antunes MJ, BucciarelliDucci C, Bueno H, et al. 2017 ESC Guidelines for the management of acute myocardial infarction in patients presenting with ST-segment elevation. Eur Heart J. 2018;39(2):119-77.

3. Navinan MR, Mendis S, Wickramasinghe S, Kathirgamanathan A, Fernando T, Yudhisdran J. Inflammation in ST- elevation myocardial infarction: risk factors, patterns of presentation and association with clinical picture and outcome, an observational study conducted at the Institute of Cardiology-National Hospital of Sri Lanka. BMC Cardiovasc Disord. 2019;19(1):111.

4. Aurelian SV, Adrian M, Andercou O, Bruno S, Alexandru O, Catalin T, Dan B. Neutrophil-to-Lymphocyte Ratio: A Comparative Study of Rupture to Nonruptured Infrarenal Abdominal Aortic Aneurysm. Ann Vasc Surg. 2019 Jul;58:270-275. doi: 10.1016/j. avsg.2018.11.026. Epub 2019 Feb 13. PMID: 30769065.

5. Reindl M, Reinstadler SJ, Feistritzer HJ, Klug G, Tiller C, Mair J, Mayr A, Jaschke W, Metzler B. Relation of inflammatory markers with myocardial and microvascular injury in patients with reperfused ST-elevation 
myocardial infarction. Eur Heart J Acute Cardiovasc Care. 2017 Oct;6(7):640-649. doi: 10.1177/2048872616661691. Epub 2016 Jul 20. PMID: 27440935.

6. Thygesen K, Alpert JS, Jaffe AS, Chaitman BR, Bax JJ, Morrow DA, et al. Fourth universal definition of myocardial infarction (2018). Eur Heart J. 2019;40(3):237-69.

7. Collet JP, Thiele H, Barbato E, Barthélémy O, Bauersachs J, Bhatt DL, Dendale P, Dorobantu M, Edvardsen T, Folliguet T, Gale CP, Gilard M, Jobs A, Jüni P, Lambrinou E, Lewis BS, Mehilli J, Meliga E, Merkely B, Mueller C, Roffi M, Rutten FH, Sibbing D, Siontis GCM; ESC Scientific Document Group. 2020 ESC Guidelines for the management of acute coronary syndromes in patients presenting without persistent ST-segment elevation. Eur Heart J. 2021 Apr 7;42(14):1289-1367. doi: 10.1093/eurheartj/ehaa575. Erratum in: Eur Heart J. 2021 May 14;42(19):1908. Erratum in: Eur Heart J. 2021 May 14;42(19):1925. Erratum in: Eur Heart J. 2021 May 13;: PMID: 32860058.

8. Anchidin OI, Nemes A, Molnar A, Rosianu A, Rosianu $\mathrm{SH}$, Pop D. Are cardiovascular rehabilitation programs implemented in young patients with acute coronary syndromes following revascularization procedures? Balneo Research Journal. 2020;11(2):133-40.

9. Gue YX, Kanji R, Gati S, Gorog DA. MI with Nonobstructive Coronary Artery Presenting with STEMI: A Review of Incidence, Aetiology, Assessment and Treatment. Eur Cardiol. 2020;15:e20. Published 2020 Apr 30. doi:10.15420/ecr.2019.13

10. Di Stefano R, Di Bello V, Barsotti MC, Grigoratos C, Armani C, Dell'Omodarme M, Carpi A, Balbarini A. Inflammatory markers and cardiac function in acute coronary syndrome: difference in ST-segment elevation myocardial infarction (STEMI) and in non-STEMI models. Biomed Pharmacother. 2009 Dec;63(10):773-80. doi: 10.1016/j.biopha.2009.06.004. Epub 2009 Oct 13. PMID: 19906505.

11. De Luca G, Suryapranata H, Van't Hof AWJ, De Boer MJ, Hoorntje JCA, Dambrink JHE, et al. Prognostic assessment of patients with acute myocardial infarction treated with primary angioplasty: Implications for early discharge. Circulation. 2004;109(22):2737-43.

12. Dekker MS, Mosterd A, Van 'T Hof AWJ, Hoes AW. Novel biochemical markers in suspected acute coronary syndrome: Systematic review and critical appraisal. Heart. 2010;96(13):1001-10.

13. Reichlin T, Hochholzer W, Stelzig C, Laule K, Freidank $\mathrm{H}$, Morgenthaler $\mathrm{NG}$, et al. Incremental Value of Copeptin for Rapid Rule Out of Acute Myocardial Infarction. J Am Coll Cardiol [Internet]. 2009;54(1):60-8.

14. Zdrenghea D, Pop D, Mitu F. Cardiologie preventiva si recuperare cardiovasculara. Clusium; 2020.

15. Subiela JV, Torres SH, De Sanctis JB, Hernández N. Cardiorespiratory responses, nitric oxide production and inflammatory factors in patients with myocardial infarction after rehabilitation. Nitric Oxide. 2018 Jun 1;76:87-96. doi: 10.1016/j.niox.2018.03.006. Epub 2018 Mar 10. PMID: 29534920.
16. Zdrenghea D, Poantă L, Pop D, Zdrenghea V, Zdrenghea M. Physical training--beyond increasing exercise capacity. Rom J Intern Med. 2008;46(1):17-27. PMID: 19157267. 